\title{
ABUTMENT MATERIAL ON FRACTURE STRENGTH OF IMPLANT-SUPPORTED CANTILEVERED ZIRCONIA AND METAL FRAMEWORKS
}

\author{
Emral GC*, Muhtarogullari $\mathbf{M}^{* *}$, Aktas $\mathbf{G}^{* *}$, Guncu MB ${ }^{* *}$, Canay $\mathbf{S}^{* *}$
}

*Tepebasi Oral Health and Teeth Hospital, Ankara, Turkey

** Department of Prosthodontics, Faculty of Dentistry, Hacettepe University, Ankara, Turkey

Abstract

The aim of this invitro study was to evaluate the fracture strength of implant-supported cantilevered zirconia and metal frameworks with different connector areas on zirconia and titanium abutments. A total of 60 cantilevered implantsupported three unit frameworks were fabricated and divided into three groups (TZ: titanium abutment-zirconia framework, ZZ: zirconia abutment-zirconia framework, and TCrCo: titanium abutment-metal framework). Samples from each group were divided into two subgroups $(n=10)$ according to the size of the connector area; $9 \mathrm{~mm}^{2}$ and $15 \mathrm{~mm}^{2}$. All cantilevered frameworks were cemented and loaded in a universal testing machine until the framework was fractured or decemented. A two-way analysis of variance was used to analyze the fracture force and the relationship between connector dimension and abutment material. The results of fracture strength tests showed that mean fracture loads were approximately $188.73 \mathrm{~N}, 480.86 \mathrm{~N}, 234.41 \mathrm{~N}, 406.03 \mathrm{~N}$, $936.55 \mathrm{~N}$, and $924.36 \mathrm{~N}$ for TZ-9, TZ-15, ZZ-9, ZZ-15, TCrCo-9, and TCrCo-15, respectively. There was a statistically significant difference in fracture strength between TZ-9 and TZ-15, and between ZZ-9 and ZZ-15 ( $p \leq 0.05)$. In contrast, the difference in the fracture strength of TCrCo- 9 and TCrCo-15 was not statistically significant. An increase in the crosssectional area of the connector affected the fracture strength of the implant-supported cantilevered zirconia framework.

\section{Results}

In the present study, the effects of two different connector surface areas of zirconia and chromium cobalt superstructures on the supporting titanium and zirconium abutments were examined. The results are presented in Table 1. When considering the change in cross-sectional area of the connector, the differences in fracture strength between TZ-9 and TZ-15, and between ZZ-9 and ZZ-15 were statistically significant $(p \leq 0.05)$. In contrast, the difference in the fracture strength of TCrCo-9 and TCrCo-15 was not statistically significant.

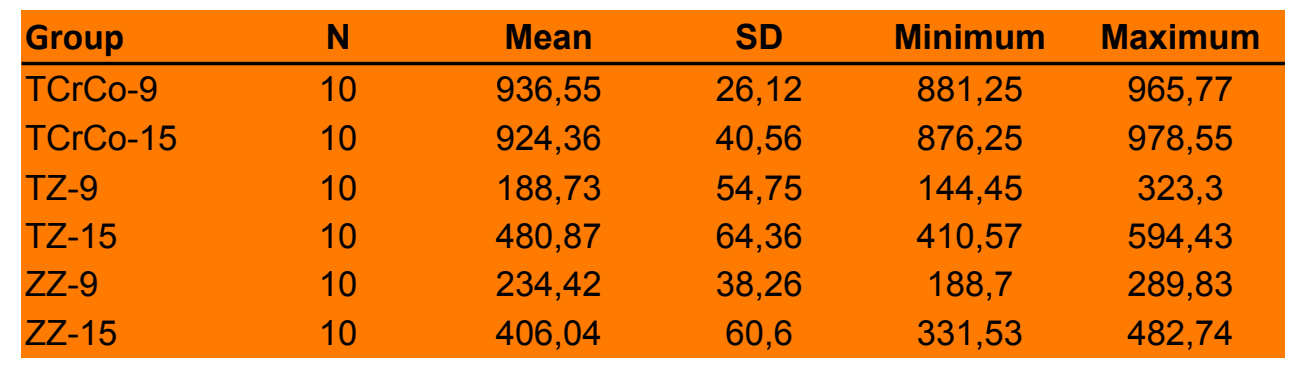

Table1.Descriptive statistics of fracture strengths $(\mathrm{N})$ values for all groups. TCrCo: titanium abutment-metal framework TZ: titanium abutment-zirconia framework, ZZ: zirconia abutment-zirconia framework, 9 or 15 represents connector size area.

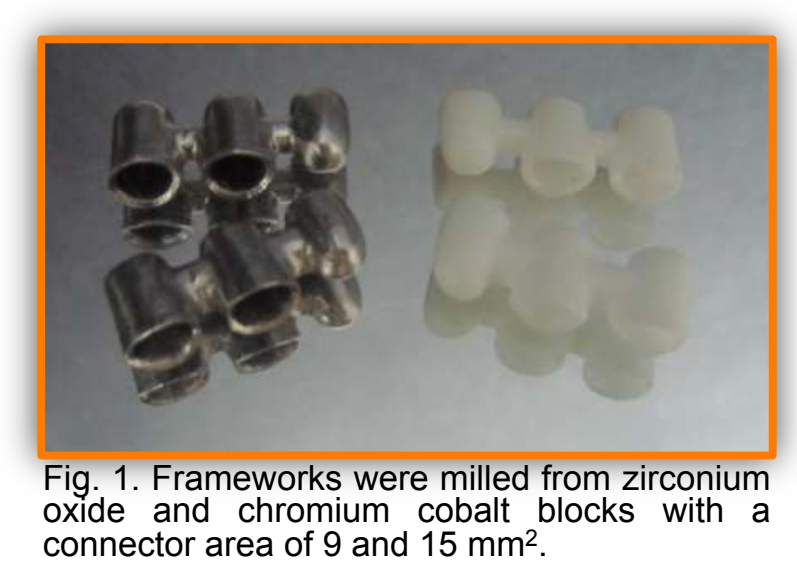

\section{Background and Aim}

The development of CAD-CAM systems for dentistry has promoted the use of zirconia, instead of metal substructures, as a strong core with good esthetics, excellent biocompatibility, and high mechanical properties, even in the posterior region. 1-3 Increasing the dimensions of the connector area would have a beneficial effect on the strength of a zirconia reconstruction; however, due to reduced vertical dimension, this is not always possible. In addition to connector area, the abutment material that supports the restorations may play a role in the fracture strength of cantilevered restorations. The aim of this present study was to assess the influence of the framework cross-sectional area and abutment material on the fracture strength of implant-supported cantilevered zirconia and metal frameworks.

\section{Methods and Materials}

A total of 60 cantilevered implant-supported three unit frameworks were fabricated and divided into three groups (TZ: titanium abutment-zirconia framework, ZZ: zirconia abutment-zirconia framework, and TCrCo: titanium abutment-metal framework). Frameworks were designed as three-unit cantilevered FPDs, replacing two premolars and one molar with a reduced span length of $7 \mathrm{~mm}$ and a connector area of 9 or $15 \mathrm{~mm}^{2}$ for each group (Fig.1). Samples from each group were divided into two subgroups $(n=10)$ according to the size of the connector area. All cantilevered frameworks were cemented with zinc-phosphate cement (Adhesor, Spofa Dental, Praque, Czech Republic) according to manufacturer's instructions and loaded in a universal testing machine until the framework was fractured or decemented. A two-way analysis of variance was used to analyze the fracture force and the relationship between connector dimension and abutment material.

\section{References}

Within the limitations of this study, it could be withdrawn;

- $15 \mathrm{~mm}^{2}$ connector surface area zirconia superstructure with cantilever design have reasonable fracture strength.

- Increasing the connector surface area (from $9 \mathrm{~mm}^{2}$ to $15 \mathrm{~mm}^{2}$ ), increase the fracture strength of zirconia superstructure.

- Abutment material did not affect the fracture strength of the zirconia superstructure.
Beuer F, Steff B, Naumann M, Sorensen JA. Load-bearing capacity of all-ceramic three-unit fixed partial dentures with different computer-aided design (CAD)/computer-aided manufacturing (CAM) fabricated framework materials. Eur J Oral Sci 2008;116:381-86. Raigrodski A. Clinical and laboratory considerations for the use of CAD/CAM Y-TZP-based restorations. Pract Proced Aesthet Dent 2003;15:469-76.

3. Wolfart S, Harder S, Eschbach S, Lehmann F, Kern M. Four-year clinical results of fixed dental prostheses with zirconia substructures (Cercon): end abutments vs. cantilever design. EurJ Oral Sci 2009;117:741-49. 